\title{
Nesting habitat enhancement for wild bees within soybean fields increases crop production
}

\author{
Michael J. Cunningham-Minnick ${ }^{1}$, Valerie E. Peters ${ }^{1,2}$, Thomas O. CRist ${ }^{1}$ \\ ${ }^{1}$ Department of Biology, Miami University, Pearson Hall \#212, 700 E High St, Oxford, OH 45056, USA \\ ${ }^{2}$ Department of Biological Sciences, Eastern Kentucky University, Richmond, KY, USA
}

Received 17 December 2018 - Revised 22 June 2019 - Accepted 10 September 2019

\begin{abstract}
Bee diversity is declining in agricultural landscapes, altering pollination services that may support or enhance crop yields. Pollination services provided by wild bees are often limited to field margins adjacent to natural habitats, but methods to increase pollinators and their ecosystem services within field interiors remain elusive. Evidence is growing that wild bees enhance yields of flowering crops, including soybean (Glycine max (L.) Merrill). We tested responses of bee communities and soybean yield following pollinator exclosure and nesting manipulation experiments within production areas of the United States. We found that pollinator exclosures resulted in lower seed yield of soybean plants, and providing nesting substrate resulted in a yield increase as well as increases in groundnesting bees. We provide evidence for soybean-associated bees and suggest these species may benefit from supplemental nesting substrate within production areas and increase soybean yields.
\end{abstract}

\section{Agroecosystems / Exclosure / Food security / Pollination / Bee communities / Nesting habitat provision}

\section{INTRODUCTION}

Habitat loss is a driving force of declining bee diversity and pollination services to crops and wild plants (Klein et al. 2007; Potts et al. 2010; Winfree et al. 2007a). Agricultural intensification displaces habitat for native bees and disrupts mutualisms through the reduction of plant diversity (Burkle et al. 2013; Garibaldi et al. 2011; Kremen et al. 2002). Therefore, pollinators rely on seminatural habitat bordering production areas for food and nesting resources in agricultural landscapes. These refuges support local pollinator communities and enhance ecosystem services to

Electronic supplementary material The online version of this article (https://doi.org/10.1007/s13592-019-00691-y) contains supplementary material, which is available to authorized users.

Corresponding author: M. Cunningham-Minnick, minnicmj@miamiOH.edu

Handling editor: David Tarpy adjacent crop fields (Diekötter et al. 2013; Tscharntke et al. 2005; Winfree et al. 2007b). However, unless bees and other pollinators can inhabit production areas, growers cannot take full advantage of the free crop pollination services provided by native bees (Christmann and AwHassan 2012; Sardiñas et al. 2016). Intensive management practices, loss of floral diversity, and restrictions of nesting substrates act as barriers that prevent pollinators access to crop field interiors. Resident bee communities of agricultural landscapes and their pollination services could be enhanced with greater knowledge of their limiting resources (Burkle et al. 2017).

Agricultural intensification in North America is associated with large monocultures of selfpollinating crops including the legume, soybean (Glycine max). In general, legumes are bee pollinated, and even self-pollinating legumes have outcrossing potential (Suso et al. 2016; Smýkal et al. 2018). Reduced floral size and reward 
(nectar and pollen) associated with domestication often result in decreased insect attraction and pollination (Meyer and Purugganan 2013). Nonetheless, honeybees can increase soybean production, but variation in yield differences between cage and field experiments suggested a cultivardependent pollination role for wild bees (Ahrent and Caviness 1994; Erickson 1975; Erickson et al. 1978; Free 1993). Pollination enhancement of soybeans by wild bees was further demonstrated in cage experiments (Roumet and Magnier 1993) and recently inferred in crop fields (Milfont et al. 2013; Monasterolo et al. 2015, Zelaya et al. 2018). Dennis (2018) found increases in soybean seed set but not overall yield. Although wild bees may enhance soybean pollination and yield, bee communities within agricultural landscapes are dependent on resources of nearby semi-natural habitats (Winfree et al. 2007a). Without food and nesting resources within the production area, it is unlikely that soybeans and other cultivated crops can benefit from wild bee services (Burkle et al. 2017).

Improving habitat quality along field margins may increase bee abundance and diversity, thereby increasing spillover of pollination services to production areas (Garibaldi et al. 2011; Kennedy et al. 2013; Tscharntke et al. 2005; Winfree et al. 2007b). In large fields, however, pollination by bees declines exponentially with distance from semi-natural habitats (Garibaldi et al. 2011; Ricketts et al. 2008). This is partly due to foraging limitations, with larger bee species capable of foraging farther distances than smaller bees (Greenleaf et al. 2007). Typical foraging distances are context dependent on the spatial variation of the nest location in relation to host floral resources (Everaars et al. 2018). Foraging distances for native and smaller bee species are largely unknown. For example, a review by Greenleaf et al. (2007) categorized typical foraging distances as $50 \%$ of maximum foraging distances due to insufficient studies available for the review. However, mark-recapture studies of native solitary bees suggest typical foraging ranges can be much less $(<1 \%)$ than these predicted values (Sardiñas et al. 2016), and empirical studies suggest that small and medium-sized bees primarily forage less than $100 \mathrm{~m}$ from nests (Cutler et al. 2015, Steffan-Dewenter and Tscharntke 1999).
This contradiction likely reflects bees balancing energy expenditures to acquire pollen (Everaars et al. 2018), and the disproportionately greater foraging distances of large and often managed bee species (Greenleaf et al. 2007). Bees are more likely to inhabit provisioned nests that are close to a used resource (Gathmann and Tscharntke 2002) and will nest within flowering crop fields that are intensively managed (Julier and Roulston 2009, Krug et al. 2010, Sardiñas et al. 2016). Therefore, nesting sites could be established in exposed soil following crop planting (Cane 1991), but the lack of floral resources limits nest establishment by early-season species. Late-season solitary and multivoltine bees that search for nesting sites before or during early soybean flowering are limited by dense crop cover and little exposed soil nesting substrate. Thus, pollination services in large, intensively managed fields are likely restricted for most wild bees (Tscharntke et al. 2005).

Collectively, the effects of soybean floral domestication, limited bee foraging ranges, and intensive management lead to the assumption that soybean production areas are inhospitable habitats for bees (Garibaldi et al. 2011; Kennedy et al. 2013; Kremen et al. 2002; Tscharntke et al. 2005). However, there is growing evidence for a community of ground-nesting social and solitary bees that is tolerant of production areas (Gill and O’Neal 2015; Wheelock et al. 2016; Dennis 2018; Raudenbush et al. 2018). This includes species that found colonies early in the season, as well as solitary bees with emergence times that coincide with soybean flowering. Although it is unknown if bee assemblages depend more on soybean crops or field margins, yields in other crop systems are higher when bees nest within fields (Cane 2008; Julier and Roulston 2009; Sardiñas et al. 2016).

Here, we tested two hypotheses on the roles of wild bees in soybean pollination and yield. First, we hypothesized that bee pollination enhances soybean yield over wind or self-pollination. Second, we tested whether greater nesting substrate availability within intensively managed production areas increases bee diversity, bee abundance, and soybean yield. We sampled the bee community and quantified bee effects on soybean yield using pollinator exclosures over 
soybean flowers in fields with and without nesting habitat enhancements for ground and cavitynesting species. We predicted that preventing pollinators access to soybean flowers would result in a lower yield compared to plants with flowers available to pollinators. We also predicted that soybeans in fields with supplemental nesting substrate would have increased soybean yield due to increased abundance of bee pollinators and decreased foraging distance between nests and crop plants.

\section{MATERIALS AND METHODS}

Study sites The study was conducted in summer 2014 at the Ecology Research Center (ERC) of Miami University near Oxford, Ohio, USA $\left(39.5325^{\circ} \mathrm{N},-84.7232^{\circ} \mathrm{W}\right.$; Online Resource 1$)$. The ERC consists of temperate and secondary growth deciduous forest, soybean and corn agricultural fields, old field, and lawn. We established four sites of experimental soybean fields in a paired plot design ( $n=8$ plots) to account for variation in surrounding environmental factors. Each site consisted of a control and enhancement plot, with each plot $60 \times 70 \mathrm{~m}(0.4 \mathrm{ha})$ in size. Indeterminate glyphosate-resistant Steyer ${ }^{\circledR}$ variety 835 BCU77 soybeans without a seed coating were planted in $76-\mathrm{cm}(30-i n$.) rows in all plots. We implemented flowerless buffers of 10-15 m around each plot with weekly tillage or mowing to reduce the effects of nearby pollen and nesting sources on the nesting enhancement treatments of the plot pairs. Short buffers were used to ensure that all species in the adjacent area of both plots could access the center of either plot in a site. To reduce bee visitation between plot pairs, the plots within a site were positioned diagonally (Online Resource 1). The distance between sites varied from 0.18 to $0.80 \mathrm{~km}$.

Nesting habitat enhancements Nesting treatments were applied within crop fields before (13th -17th July) soybean flowering to target late-season and multivoltine bee species. Although social species (early-season founders) may nest in soil, the lack of floral resources in crop fields during spring and early summer would prevent these bees from using early-season nest treatments. Centered within each plot, a $1 \times 10$-m rectangular strip of ground was cleared by hand-pulling soybean plants to provide habitat for ground-nesting bees. Nest treatment areas in control plots, abbreviated $\mathrm{N}$-, were covered with $0.125 \mathrm{~mm}^{2}$ white, nylon netting to exclude ground-nesting insects with minimal alteration to soil properties (i.e. sunlight, soil temperature and moisture), while nest treatment areas of experimental plots, abbreviated $\mathrm{N}+$, were not covered.

Bee community samplingBees were sampled weekly from 31st July - 4th September using $0.59 \mathrm{~L}(20 \mathrm{oz})$ fluorescently painted pan traps (white, yellow, and blue; Droege 2008). Four raised platforms were placed in each plot halfway between nest treatment corners and the nearest plot corner (along the diagonals). Three pan traps (one of each color) containing soapy water were placed on each platform for $24 \mathrm{~h}$. Platform height was adjusted weekly to vegetation height (Geroff et al. 2014). Bees from all four platforms were pooled for analyses.

Pollinator exclosures To evaluate the effects of pollinators on soybean production, pollinator access to soybean plants was manipulated in a paired design within each plot (Dennis 2018, Kalisz and Vogler 2003, Milfont et al. 2013). On 22nd July, when the first flower was observed at sites, $1-\mathrm{m}$ tall mesh cages constructed with 0.125 $\mathrm{mm}^{2}$ white, nylon netting were placed over $1-\mathrm{m}$ segments of planting rows of soybean plants $(\sim 10$ adjacent plants), hereafter, $\mathrm{C}+$. Another 1-m row of plants directly adjacent to $\mathrm{C}+$ plants were open to pollinators and served as the control plants, indicated as C-. We removed all insects and eggs on $\mathrm{C}+$ and $\mathrm{C}$ - plants immediately prior to caging soybeans and visually inspected cages for pests and structural integrity weekly. Plots within each site had identical configurations of mesh cages, with one to the east and one to the west of the plot center. Assigned randomly, two sites contained mesh cages at distances of 6 and $18 \mathrm{~m}$ from each plot center, while the other two sites had cages 12 and $24 \mathrm{~m}$ from plot centers. Mesh cages were removed from 2nd - 8th September once soybeans were finished flowering. Average plant height was recorded when cages were removed 
to evaluate potential effects of herbivory (Cplants) and shading ( $\mathrm{C}+$ plants $)$ on plant growth.

Soybean harvest To quantify the effects of nest enhancements on soybean pollination, a transect of 10 soybean plants was harvested $10 \mathrm{~m}$ and 20 $\mathrm{m}$ east and west of nest treatments in all plots for a total of four harvested transects per plot. Within each transect, one soybean plant was sampled every 10 plants $(\sim 1 \mathrm{~m})$ along the row to represent plants across the entire length of the nest treatment $(10 \mathrm{~m}) . \mathrm{C}+$ and $\mathrm{C}$ - plants were harvested following senescence to evaluate effects of pollinators on seed set. To quantify fruit and seed set, the number of pods and seeds within each pod, respectively, were recorded for all sampled plants. Aborted pods were not counted. To quantify seed mass, seeds of each plant were pooled and oven dried at $100^{\circ} \mathrm{C}$ for $24 \mathrm{~h}$ to achieve constant mass ( $0 \%$ moisture).

Bee community analysesSpecies richness, abundance, diversity, and ground-nesting bees were analyzed using linear and generalized linear mixed effects models in $\mathrm{R}$ version 3.3.1 ( $\mathrm{R}$ Core Team 2016) with the lme 4 package (Bates et al. 2015). We tested hypotheses that nest treatments affected response variables by performing likelihood ratio tests of models with and without the nest treatment variable. All models had random site intercepts to account for differences in sitespecific factors, such as variation in the surrounding environmental factors (e.g. vegetation type, other available floral resources, soil differences). Response variables included abundance, rarified species richness, Shannon's Index, and groundnesting species richness and abundance of the bee community. Species richness and abundance responses were modeled using Poisson error distributions.

Soybean yield analysisThe effects of pollinators on soybean yield were determined by modeling yield differences between $\mathrm{C}+$ and $\mathrm{C}$ - plants using maximum likelihood estimation. All model selection was performed using the AICcmodavg package (Mazerolle 2016). Soybean yield responses for $\mathrm{C}+$ models included seed set, fruit (pod) set, seed mass, and quantity of pods with one, two, three, and four seeds. All models $\leq 2$ AICc units of the best model (lowest AICc) were evaluated and the best model was used in analyses (Online Resource 2). We used the response $\ln \left(y_{i}\right)$ $-\ln \left(x_{i}\right)$, where $y_{i}$ is the average per plant yield response among $1 \mathrm{~m}$ of $\mathrm{C}$ - plants of cluster $i$, where $i=1: 16$ (two clusters per plot), and $x_{i}$ is the average yield response of the adjacent $1 \mathrm{~m}$ of $\mathrm{C}+$ plants of cluster $i$. Models included a random intercept of site or plot to account for spatial variation that was unrelated to pollinator exclusion. Results are reported as mean intercepts with 95\% CIs and interpreted as a significant effect size if CIs do not include zero.

To determine if distance from nest enhancements affected soybean yield, likelihood ratio tests were performed on linear mixed effects models with and without a nest treatment variable. The average production per plant within a transect ( 1 transect $=10$ plants pooled), was logtransformed to meet the assumptions of normality. Site was included as a random effect and distance from plot centers (10 and $20 \mathrm{~m}$ ) was a continuous fixed effect in all models.

Plant-pollinator analysisTo determine which bee species were most associated with soybean yield, we analyzed seed set responses to nest treatment, distance from plot center, and the abundance of individual bee species. Seed set was the average number of seeds per plant harvested from all four transects within a plot ( $n=40$ plants). We allowed intercepts to randomly vary with site. The response variable, seed set, and the predictor, individual bee species abundance, were log-transformed. Since the most common species are likely responsible for crop pollination (Kleijn et al. 2015), only bee species that were present in every plot were included in the analyses. Model selection was conducted as described above. Chisquared test statistics of likelihood ratio tests are reported for the final model predictors.

\section{RESULTS}

We sampled 1742 individual bees within flowering soybean fields and used 1724 individuals of 53 species for analyses (Online Resource 3). 
Due to uncertainty in identification, seven Lasioglossum (Dialictus) males and 11 individuals with missing body parts were omitted from analyses. The effect of nest treatments differed depending on the bee group (Table 1), but did not affect rarified species richness $\left(\chi^{2}(1)=0.13, p=\right.$ 0.72 ) or Shannon's Index $\left(\chi^{2}(1)=0.06, p=0.80\right)$, but tended to increase overall abundance $\left(\chi^{2}(1)=3.35, p=0.07\right)$ of the bee community. Ground-nesting bee abundance in $\mathrm{N}+$ plots (mean \pm SE: $43.6 \pm 6.6$ ) was greater than $\mathrm{N}$ - plots $\left(\right.$ mean \pm SE: $\left.38.7 \pm 6.4 ; \chi^{2}(1)=4.93, p<0.05\right)$. Three bee species, Lasioglossum callidum, Lasioglossum hitchensi, and Agapostemon virescens, were more abundant in N+ plots. Species richness of ground-nesting bees was not different between $\mathrm{N}$ - and $\mathrm{N}+$ plots $\left(\chi^{2}(1)=0.51\right.$, $p=0.47)$. We found fewer honey bees, Apis mellifera, in $\mathrm{N}+$ compared to $\mathrm{N}$ - plots.

Yield differences between $\mathrm{C}+$ and $\mathrm{C}$ - plants demonstrated that pollinators increased seeds by $23.1 \%$ (effect size $=0.160 \pm 0.154$ ) and pods by $24.4 \%(0.171 \pm 0.154)$, although there was a trend of decreasing seed mass in C- plants $(-0.053 \pm$ 0.078) (Fig. 1). Increases in C- seed and pod set were primarily due to increases in pods with two $(0.430 \pm 0.170)$ seeds, although pods with one $(0.657 \pm 0.791)$, three $(0.131 \pm 0.136)$ and four $(0.634 \pm 0.732)$ seeds tended to increase when exposed to pollinators (see Online Resource 4 for untransformed values). The average $( \pm \mathrm{SE})$ heights of $\mathrm{C}+(73 \pm 3 \mathrm{~cm})$ and $\mathrm{C}-(72 \pm 2 \mathrm{~cm})$ plants were similar and did not warrant further consideration for statistical analysis.

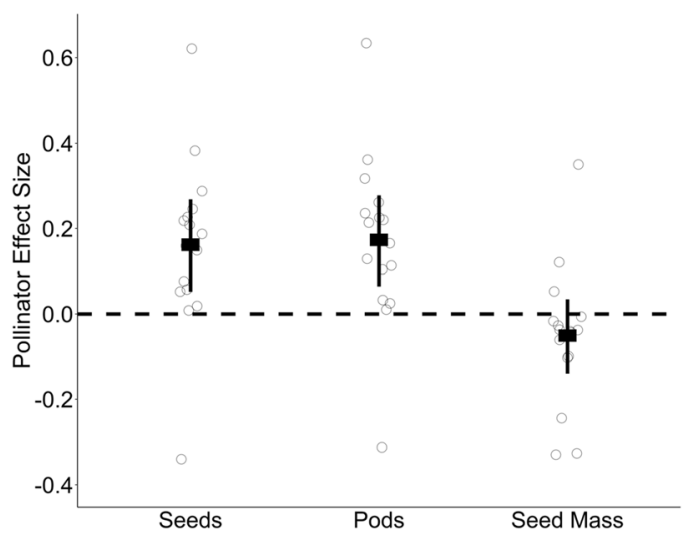

Figure 1. Intercepts of soybean production models with and without pollinators. Responses (seed set, pod set, and mass per seed) are evaluated as $\ln$ (pollinators)In(no pollinators), such that positive values indicate increased production when pollinators are allowed flower access. Each hollow circle represents averaged response of one cluster of soybean plants. Solid squares indicate averages, and vertical lines represent limits of $95 \%$ CI.

$\mathrm{N}+$ had increased soybean seed and pod production, but differences were not statistically significant. $\mathrm{N}+$ increased seeds per plant on average by $31.0 \%$ at $10 \mathrm{~m}$ and $28.7 \%$ at $20 \mathrm{~m}$ from nest treatments $\left(\chi^{2}(1)=3.47, p=0.06\right)$ and increased pod set $\left(\chi^{2}(1)=3.16, p=0.08\right)$ (Fig. 2). Seed mass also tended to increase in $\mathrm{N}+$ plots $\left(\chi^{2}(1)=2.57, p=0.11\right)$. Changes in counts of pods with one, two, three, or four seeds were not uniform (Fig. 3). There was no effect of $\mathrm{N}+$ on number of pods with one $\left(\chi^{2}(1)=0.20, p=\right.$ $0.65)$, two $\left(\chi^{2}(1)=1.29, p=0.26\right)$, or four seeds

Table I. Response means and standard errors of model with and without supplemental nesting habitat. Chi-squared statistics and associated $p$ values are derived from likelihood ratio tests between models.

\begin{tabular}{lllll}
\hline \multicolumn{1}{c}{ Response } & Control \pm SE & Nesting Enhancement \pm SE & Chi-squared Statistic & p value \\
\hline Ground bee abundance & $38.7 \pm 6.4$ & $43.6 \pm 6.6$ & 0.44 & 0.51 \\
Ground bee richness & $9.3 \pm 1.0$ & $10.1 \pm 0.9$ & 0.64 & 0.42 \\
Overall richness & $12.1 \pm 1.1$ & $12.5 \pm 1.1$ & 0.09 & 0.77 \\
L. callidium abundance & $0.9 \pm 0.3$ & $2.6 \pm 0.7$ & 14.89 & $<0.0005$ \\
L. hitchensi abundance & $15.6 \pm 3.7$ & $19.9 \pm 4.4$ & 8.86 & $<0.005$ \\
A. virescens abundance & $1.5 \pm 0.4$ & $2.9 \pm 0.8$ & 7.93 & $<0.005$ \\
A. mellifera abundance & $2.6 \pm 0.8$ & $1.4 \pm 0.5$ & 5.97 & $<0.05$ \\
\hline
\end{tabular}



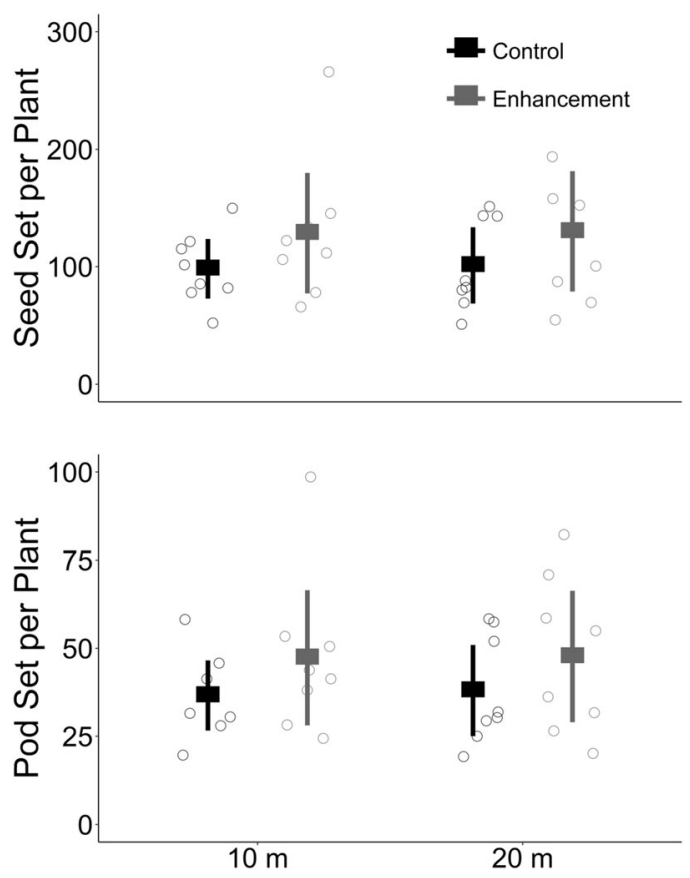

Figure 2. Distribution of seed (upper) and pod (lower) set per plant with (gray) and without (black) nesting substrate enhancements $10 \mathrm{~m}$ and $20 \mathrm{~m}$ from plot centers. Hollow circles represent average of one transect (10 plants). Vertical lines indicate 95\% CIs and solid squares show means.

$\left(\chi^{2}(1)=2.30, p=0.13\right)$ seeds. Instead, seed and pod set increases were due to higher quantities of pods with three seeds $\left(\chi^{2}(1)=4.03, \mathrm{p}<0.05\right)$.

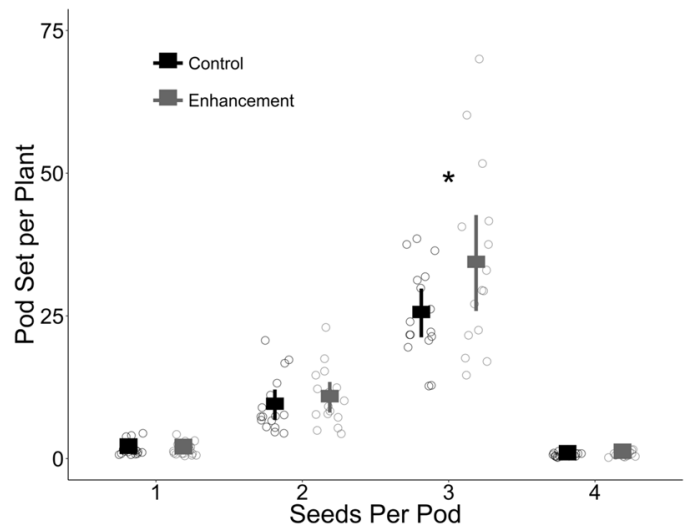

Figure 3. Pod set (y-axis) with one, two, three, and four seeds (x-axis) with (gray) and without (black) nesting substrate enhancements. Vertical lines indicate $95 \%$ CIs and solid squares show means. ${ }^{*} P<0.05$.
Statistical models of individual bee species abundances and average soybean seed set resulted in four competing models (Table 2). Nest treatment was the strongest predictor and was included in all models. The abundance of L. callidum was a positive predictor of seed set in all models. Apis mellifera was present in two models and Lasioglossum imitatum in one model, showing weak associations with increased seed set. Lasioglossum versatum and Augochlora pura were negatively associated with seed set.

\section{DISCUSSION}

Effects of soybean flower access and nesting enhancements We demonstrated positive relationships between pollinator access and soybean fruit and seed production. Soybean plants exposed to pollinators while flowering yielded a $23 \%$ higher seed set and $24 \%$ higher fruit set compared to those excluded from pollinators, regardless of nest treatments. This is consistent with previous findings that wild pollinators play a role in cultivated soybean pollination (Milfont et al. 2013; Monasterolo et al. 2015). Milfont et al. (2013) found increases in pods with three seeds with supplemental pollinators, while we observed increases in pods with two seeds when soybean flowers were exposed to ambient pollinators. Though this difference could be cultivar-dependent, it suggests pollination limitation of soybeans by native bees outside of production areas. Although we did not control herbivory or shade, there was no observed difference in heights or damage of caged and open plants (Dennis 2018).

An association of some wild bee species with soybean suggests that use of soybean flowers enhances their distribution and abundance within agricultural landscapes (Kleijn et al. 2015). We did not find a relationship between overall bee diversity and nesting enhancement, but the trend of increased bee abundance resulted from groundnesting species. Of the 53 bee species sampled from the soybean fields, only 10 species were found to occur in every plot, which together comprised $81 \%$ of the total bee abundance (Table 3 ). Of these species, three increased in abundance with nesting enhancements: L. callidum, L. hitchensi, and A. virescens. All are ground- 
Table II. Competing models for natural log responses of average seed set within plots ( $n=40$ plants per response value). Predictor coefficients with standard errors and Chi-squared $\left(\chi^{2}\right)$ statistics with associated $p$ - values from likelihood ratio tests are provided for each variable within a model. Shading indicates one competing model. $\chi^{2}$ statistic without asterisks indicates a $\mathrm{p}$ value $>0.05$.

\begin{tabular}{|c|c|c|c|c|c|c|c|c|}
\hline Species & Coef & $\chi^{2}(1)$ & Coef & $\chi^{2}(1)$ & Coef & $\chi^{2}(1)$ & Coef & $\chi^{2}(1)$ \\
\hline Intercept & $4.604 \pm 0.110$ & $N A$ & $4.585 \pm 0.113$ & $N A$ & $4.587 \pm 0.114$ & $N A$ & $4.593 \pm 0.107$ & $N A$ \\
\hline Nest Enhancement & $0.240 \pm 0.025$ & $41.76^{* * * *}$ & $0.254 \pm 0.025$ & $43.00 * * * *$ & $0.249 \pm 0.024$ & $43.83 * * * *$ & $0.248 \pm 0.025$ & $42.65 * * * *$ \\
\hline Lasioglossum callidium & $0.068 \pm 0.022$ & $8.49 * * *$ & $0.062 \pm 0.021$ & $7.76^{* *}$ & $0.072 \pm 0.021$ & $10.00^{* * *}$ & $0.065 \pm 0.022$ & $7.94 * * *$ \\
\hline Augochlora pura & $-0.054 \pm 0.018$ & $8.04 * * *$ & $-0.062 \pm 0.018$ & $10.17^{* * *}$ & $-0.050 \pm 0.019$ & $6.37 *$ & $-0.059 \pm 0.018$ & $9.17 * * *$ \\
\hline Apis mellifera & $N A$ & & $0.034 \pm 0.022$ & 2.33 & $0.046 \pm 0.022$ & $4.07 *$ & $N A$ & \\
\hline Lasioglossum versatum & $N A$ & & $N A$ & & $-0.028 \pm 0.017$ & 2.53 & $N A$ & \\
\hline Lasioglossum imitatum & $N A$ & & $N A$ & & $N A$ & & $0.024 \pm 0.021$ & 1.19 \\
\hline$\triangle \mathrm{AICc}$ & 0.00 & & 0.87 & & 1.79 & & 2.00 & \\
\hline
\end{tabular}

**** $P<0.0001$; *** $P<0.005$; ** $P<0.01$; $P<0.05$

nesting bees and comprised $42 \%$ of all sampled bees. Lasioglossum callidum and L. hitchensi are social and generalist species of the same subgenus of small-bodied sweat bees, Dialictus, while A. virescens is a late-season and communal nesting generalist. Interestingly, $85 \%$ of the individuals of $A$. virescens were male, which may forage on soybean nectar but do not actively collect pollen. Since the mechanism of soybean pollination enhancement by bees and other insects is largely unknown, it is unclear if male bees benefit yield, though males are efficient pollinators in other systems (Cane et al. 2011). We also

Table III. Rank ordered abundances of species $(n=10)$ present at all sites.

\begin{tabular}{ll}
\hline \multicolumn{1}{c}{ Species } & Total Abundance \\
\hline Lasioglossum hitchensi & 602 \\
Melissodes bimaculata & 200 \\
Augochlora pura & 167 \\
Lasioglossum versatum & 129 \\
Agapostemon virescens & 74 \\
Apis mellifera & 68 \\
Lasioglossum callidum & 58 \\
Lasioglossum imitatum & 51 \\
Halictus confusus & 30 \\
Halictus ligatus & 25 \\
\hline
\end{tabular}

observed a colony of Halictus ligatus nesting within a habitat enhancement. The typical foraging range of this small social and generalist species is unknown, but Ginsberg (1985) found that $H$. ligatus visited flowers in a nearestneighbor pattern and did not fly over available floral resources. Therefore, the bare ground enhancement likely provided suitable nesting sites within this flowering crop field. Increased abundance of dominant ground-nesting bee species suggests that nesting substrate may be a limiting factor for these bees within crop production areas.

The nesting enhancements also resulted in a $30 \%$ increase in seed and pod set 10 and $20 \mathrm{~m}$ from plot centers. Milfont et al. (2013) observed increased yield due to bees was primarily due to higher production of pods with three seeds. Considering provisioned nesting substrate also increased the presence of ground-nesting bees, our findings from both the pollinator-exclosure and nesting enhancement suggest that soybean pollination is limited by the availability of bee pollinators. Nesting enhancement was a strong predictor of increased seed set. The magnitude of the increase in seed and pod set due to nest enhancements was greater than the abundance response of ground-nesting bees, implying that other bee species were involved in soybean pollination but sampled less effectively in pan traps. 
We detected several positive associations between individual bee species and increased soybean yield, including L. callidum, which increased with nesting enhancements. Lasioglossum imitatum and A. mellifera were also significant predictors of increased soybean yield, suggesting that insect pollination of soybeans is due to the complementary effects of a diverse assemblage of pollinators. The positive associations between small sweat bees and crop yield may be a consequence of bee traits and flower morphology. Soybean flowers exhibit a closed morphology that requires maneuverability of keel petals to access floral rewards. Since Dialictus are only a few millimeters in size, they may be small enough to navigate soybean flowers to obtain pollen and nectar stores. However, not all soybeanassociated bees are small. For instance, A. mellifera is a medium-sized bee, and is a known pollinator of soybeans. Since honeybees were not a part of the experimental design, hives were located 200-800 m from experimental plot edges and often with other flowering crops in closer proximity. This is likely the source of the weak relationship between honeybees and soybean production. Alternatively, it could be due to the short handling time A. mellifera spent servicing soybean flowers (Online Resource 5). In general, the weak effect sizes of individual species suggest that many bee species are needed to enhance soybean pollination and yield, perhaps because a given bee species may visit a single flower infrequently but visits by multiple bee species increase the likelihood of pollen transfer among flowers. Nonetheless, effective pollinators of this system are likely to include the more dominant species found in every plot (Kleijn et al. 2015) with the exception of A. pura, which showed a negative relationship with soybean production and was likely a reflection of the shade from nearby forests. Such variation in species-specific bee responses supports the hypothesis that a subset of the overall ground-nesting bee assemblage is responsible for yield enhancement of soybeans.

A soybean-associated bee community. Identifying native bee species associated with soybean production areas of Midwestern North America is a recent interest (Gill and O'Neal 2015, Wheelock et al. 2016, Dennis 2018, Raudenbush et al. 2018), even though attention to wild bees within soybean crops dates back decades (Rust et al. 1980). The heterogeneous habitat types (forest, grassland, crops) surrounding our study sites and small plot size (0.40 ha) likely contributed to the high bee diversity (Online Resource 6) sampled within crops and among sites (Dauber et al. 2003). Less than 10 individuals were sampled from 37 species, suggesting most of these species are not commonly found in soybean crop fields and are unlikely to play a role in soybean pollination (Kleijn et al. 2015). Bee surveys in Ohio (Raudenbush et al. 2018), Indiana (Dennis 2018), and Iowa (Gill and O’Neal 2015) soybean fields found diverse assemblages similar to our study (Online Resource 3). Specifically, Lasioglossum (Dialictus) sp. (identified here as L. hitchensi), A. virescens, Melissodes bimaculata, and other Lasioglossum (Dialictus) species were found in high abundances in these states, supporting the notion of a soybean-associated bee community.

The associations among ground-nesting bees, soil-substrate enhancements, and increased soybean yield emphasizes the potential importance of Dialictus bees. Due to the difficulties differentiating species of Dialictus, they are often lumped as a single taxonomic unit in pollination studies (Gibbs 2011). However, four species in our study belong to Dialictus, and three of those either benefited from nesting substrate enhancements, increased soybean yield, or both. Important traits, such as sociality and foraging behaviors, vary widely among these species and highlight the need to understand their roles in soybean and other crops. We also observed Xylocopa virginica, Bombus impatiens, and M. bimaculata visiting soybean flowers, all of which are large-bodied bees and known to be under sampled with pan traps (Droege 2008; Geroff et al. 2014). Xylocopa virginica (large carpenter bee) is a communal generalist that nests in wood cavities. The small flower morphology of soybean may be attractive to this short-tongued species when within typical foraging range. In contrast, M. bimaculata is a solitary, groundnesting generalist with a seasonal activity that 
largely overlaps with soybean flowering. Despite its large size, $M$. bimaculata was the second most abundant species and we found multiple individuals in soybeans with full pollen loads on tibial scopa, which may be of soybean origin (Gill and O'Neal 2015, Rust et al. 1980). As with most Bombus spp., B. impatiens are large-bodied generalists that colonize old rodent burrows underground (Michener 2000). Bumblebees are known to forage on another mass-flowering crop that does not require insect-pollination (i.e. canola; Riedinger et al. 2015; Westphal et al. 2003) and were under sampled in Iowa soybean fields using pan traps as well (Wheelock et al. 2016). Additionally, we observed $B$. impatiens in crop fields visiting soybean flowers. Bombus impatiens is one of the few bumblebees not declining in the fragmented agricultural landscapes of the Midwestern United States (Grixti et al. 2009), and its success may be partly due to its use of crop floral resources. Although a managed species, A. mellifera is a strong flyer with long-range foraging abilities and was likely under sampled as well. Bombus impatiens (Herrmann et al. 2017), A. mellifera, and possibly others regularly forage at far distances from their nest (Greenleaf et al. 2007). Therefore, it is possible that some individuals of these species visited more than one pair of experimental plots in our study.

Implications of ground-nesting substrate enhancements for soybean production. Increased soybean yields spanned at least $20 \mathrm{~m}$ from the nesting enhancement, with only slight decreases in effect size with distance from nesting enhancements, suggesting that pollinators of soybean will use nesting substrate within the production area. Closed canopies of intensively managed fields limit bee pollination of soybean plants within foraging ranges, and likely restricts small pollinators like Dialictus to areas near the field margins (Greenleaf et al. 2007). Exposing soil within soybean production areas provided bees nesting substrate, which increases their pollination services at farther distances within the crop field.
Providing exposed soil substrate for pollinators removes crop plants. Therefore, yield increases due to bee pollination should be weighed against loss of crop area. Based on the $1-\mathrm{m}$ row of plants we sampled at 32 locations within our 0.4-ha (1-acre) plots, we estimate there were 9.0 plants $\mathrm{m}^{-1}$. Following Lee and Herbek (2005), this translates to an average of 47,950 plants within a plot of our system. Their average seed weight of 1134 seeds per kilogram (2500 seeds per pound) estimates a yield of 1.1 tons per ha (32 bushels per acre) without pollinator influence. The estimated yield in our system was 1.3 tons per ha (39 bushels per acre). The application of nesting enhancement strips resulted in a loss of 0.001 ha $(<0.0025$ acres $)$ per 0.4 ha harvested. If the observed $29.9 \%$ increase in yield due to nesting enhancements occurs throughout the plot, we expect a yield of 1.7 tons per ha ( $>50$ bushels per acre). This suggests supplemental insect pollination of soybean in a conventional system could be economically beneficial, and that the area needed for bee pollination services is small relative to the potential increase in yield.

Our findings support previous reports that several wild bee species may be associated with soybean crops (Gill and O'Neal 2015; Wheelock et al. 2016; Rust et al. 1980; Dennis 2018; Raudenbush et al. 2018), and provide further evidence of insect pollination enhancement of soybean crops. These findings indicate wild bee species play a significant role in soybean pollination and yield enhancement, especially if nesting substrate is available. We provided evidence for this at a plot scale and during the soybean bloom, but studies in larger production areas over many years are needed to determine whether this approach will support native bee populations and enhance pollination of soybeans and other crops within intensively managed agricultural landscapes. Crop rotation, tillage practices, and other crop systems should be incorporated into future studies to ensure that attracting bees into the crop field does not instead serve as an ecological trap in space or time. 


\section{ACKNOWLEDGEMENTS}

We thank the Ecology Research Center of Miami University, Ann Rypstra and the late Rodney Kolb for supporting this research, providing direction and guidance, and maintaining buffers and tending to soybean fields while providing grower perspectives, respectively. We also thank Troy Meyer, Anita Schaeffer, and Amanda McDonald for excellent field and technical services. We are appreciative of Sam Droege for his time and expertise identifying reference specimens, and Hannah Penn for helpful comments and edits on this manuscript. Funding for the study was provided by Miami University's Academic Challenge Grant and the Ohio Biological Survey.

\section{AUTHOR CONTRIBUTIONS}

All authors have conceived the study design, MCM executed the field work, and all authors contributed to the analysis and writing.

\section{COMPLIANCE WITH ETHICAL STANDARDS}

Conflict of interest The authors declare that they have no potential conflict of interest in relation to the study in this paper.

L'amélioration de l'habitat de nidification des abeilles sauvages dans les champs de soja augmente la production agricole.

agroécosystèmes / zone d'exclusion / sécurité alimentaire / pollinisation / communautés d'abeilles / habitat de nidification.

Verbessern der Nesthabitate für Wildbienen in Sojafeldern erhöht die Nutzpflanzenproduktion.

Agrar-Ökosysteme / Ausschlussfläche / Lebensmittelsicherheit / Bestäubung / Bienengemeinschaften / Nesthabitatbereitstellung.

\section{REFERENCES}

Ahrent, D. K., Caviness, C. E. (1994) Natural CrossPollination of Twelve Soybean Cultivars in Arkansas. Crop Sci. 34, 376-378
Bates, D., Maechler, M., Bolker, B., Walker, S. (2015) Fitting Linear Mixed-Effects Models Using lme4. J. Stat. Softw. 67 (1), 1-48

Burkle, L. A., Marlin, J. C., Knight, T. M. (2013) PlantPollinator Interactions over 120 Years: Loss of Species, Co-Occurrence, and Function. Science 339, $1611-1615$

Burkle, L. A., Delphia, C. M., O'Neill, K. M. (2017) A dual role for farmlands: food security and pollinator conservation. J. Ecol. 105, 890-899.

Cane, J. H. (1991) Soils of Ground-Nesting Bees ( Hymenoptera : Apoidea ): Texture, Moisture, Cell Depth and Climate. J. Kansas Entomol. Soc. 64, 406-413

Cane, J. H. (2008) A native ground-nesting bee (Nomia melanderi) sustainably managed to pollinate alfalfa across an intensively agricultural landscape. Apidologie 39, 315-323.

Cane, J. H., Sampson, B. J., Miller, S. A. (2011) Pollination value of male bees: the specialist bee Peponapis pruinosa (Apidae) at summer squash (Cucurbita pepo ). Environ. Entomol. 40 (3), 614-620.

Christmann, S., Aw-Hassan, A. A. (2012) Farming with alternative pollinators (FAP)-An overlooked win-winstrategy for climate change adaptation. Agr. Ecosyst. Environ. 161, 161-164

Cutler, G., C., Nams, V., O., Craig, P., Sproule, J., M., Sheffield, C. S. (2015) Wild bee pollinator communities of lowbush blueberry fields: spatial and temporal trends. Basic Appl. Ecol. 16, 73-85.

Dauber, J., Hirsch, M., Simmering, D., Waldhardt, R., Otte, A., Wolters, V. (2003) Landscape structure as an indicator of biodiversity: Matrix effects on species richness. Agr. Ecosyst. Environ. 98, 321-329

Dennis, B. (2018) Identifying pollinator species of Indiana soybean fields and their potential contributions to yield (Master's Thesis). Retrieved from Purdue University ePubs (Accession No. AAI10792295).

Diekötter, T., Peter, F., Jauker, B., Wolters, V., Jauker, F. (2013) Mass-flowering crops increase richness of cavity-nesting bees and wasps in modern agro-ecosystems. GCB Bioenergy 6 (3), 219-226

Droege, S. (2008) The Very Handy Manual : How to Catch and Identify Bees and Manage a Collection. USGS Native Bee Inventory Monitoring Lab

Erickson, E. H., Berger, G. A., Shannon, J. G., Robins, J. M. (1978) Honey bee pollination increases soybean yields in the Mississippi Delta Region of Arkansas and Missouri. J. Econ. Entomol. 71, 601-603

Erickson, E. H. (1975) Effect of Honey Bees on Yield of Three Soybean Cultivars. Crop Sci. 15, 84-86

Everaars, J., Settele, J., Dormann, C. F. (2018) Fragmentation of nest and foraging habitat affects time budgets of solitary bees, their fitness and pollination services, depending on traits: Results from an individual-based model. PLoS ONE 13 (2), e0188269

Free, J. B. (1993) Other Leguminosae. In: Insect Pollination of Crops ( $2^{\text {nd }}$ Edition). Academic Press, London, UK, pp 327-331 
Garibaldi, L. A., Steffan-Dewenter, I., Kremen, C., Morales, J. M., Bommarco, R., et al. (2011) Stability of pollination services decreases with isolation from natural areas despite honey bee visits. Ecol. Lett. 14, 1062-72

Gathmann, A., Tscharntke, T. (2002) Foraging ranges of solitary bees. J. Anim. Ecol. 71, 757-764.

Geroff, R. K., Gibbs, J., McCravy, K. W. (2014) Assessing bee (Hymenoptera: Apoidea) diversity of an Illinois restored tallgrass prairie: methodology and conservation considerations. J. Insect Conserv. 18, 951-964

Gibbs, J. (2011) Revision of the metallic Lasioglossum (Dialictus) of eastern North America (Hymenoptera: Halictidae: Halictini). Zootaxa 3073 , 1-216.

Gill, K. A., O’Neal, M. E. (2015) Survey of Soybean Insect Pollinators: Community Identification and Sampling Method Analysis. Environ. Entomol. 44, 488-498

Ginsberg, H. S. (1985) Foraging movements of Halictus ligatus (Hymenoptera: Halictidae) and Ceratina calcarata (Hymenoptera: Anthophoridae) on Chrysanthemum leucanthemum and Erigeron annuus (Asteraceae). J. Kansas Entomol. Soc. 58 (1), 19-26.

Greenleaf, S. S., Williams, N. M., Winfree, R., Kremen, C. (2007) Bee foraging ranges and their relationship to body size. Oecologia 153, 589-596

Grixti, J. C., Wong, L. T., Cameron, S. A., Favret, C. (2009) Decline of bumble bees (Bombus) in the North American Midwest. Biol. Conserv. 142, 75-84

Herrmann, J. D., Haddad, N. M., Levey, D. J. (2017) Testing the relative importance of local resources and landscape connectivity on Bombus impatiens (Hymenoptera, Apidae) colonies. Apidologie $\mathbf{4 8}$ (4), 545-555

Julier, H. E., Roulston, T. H. (2009) Wild bee abundance and pollination service in cultivated pumpkins: Farm management, nesting behavior and landscape effects. J. Econ. Entomol. 102, 563-573

Kalisz, S., Vogler, D. W. (2003) Benefits of autonomous selfing under unpredictable pollinator environments. Ecology 84 (11), 2928-2942

Kennedy, C. M., Lonsdorf, E., Neel, M. C., Williams, N. M., Ricketts, T. H., et al. (2013) A global quantitative synthesis of local and landscape effects on wild bee pollinators in agroecosystems. Ecol. Lett. 16, 584-599

Kleijn, D., Winfree, R., Bartomeus, I., Carvalheiro, G., Henry, M., et al. (2015) Delivery of crop pollination services is an insufficient argument for wild pollinator conservation. Nat. Commun. 6 (7414), 1-8

Klein, A. M., Vaissière, B. E., Cane, J. H., SteffanDewenter, I., Cunningham, S. A., Kremen, C., Tscharntke, T. (2007) Importance of pollinators in changing landscapes for world crops. P. Roy. Soc. BBiol. Sci. 274, 303-313

Kremen, C., Williams, N. M., Thorp, R. W. (2002) Crop pollination from native bees at risk from agricultural intensification. PNAS 99, 16812-16816
Krug, C., Alves-dos-Santos, I., Cane, J. (2010) Visting bees of Cucurbita flowers (Cucurbitaceae) with emphasis on the presence of Peponapis fervens Smith (Eucerini - Apidae) = Santa Catarina, southern Brazil. Oecol. Aust. 14 (1), 128-139.

Lee, C., Herbek, J. (2005) Estimating Soybean Yield . UK Cooperative Extension Service. AGR-188. www2.ca. uky.edu/agcomm/pubs/agr/agr188/agr188.pdf.

Mazerolle, M. J. (2016) AICcmodavg: Model selection and multimodel inference based on (Q)AIC(c). R package version 2.0-4. http://CRAN.R-project.org/package= AICcmodavg

Meyer, R. S., Purugganan, M. D. (2013) Evolution of crop species: genetics of domestication and diversification. Nat. Rev. Genet. 14, 840-852

Michener, C. D. (2000) The bees of the World ( $2^{\text {nd }}$ Edition). The John Hopkins University Press. p. 788

Milfont, M. O., Rocha, E. E. M., Lima, A. O. N., Freitas, B. M. (2013) Higher soybean production using honeybee and wild pollinators, a sustainable alternative to pesticides and autopollination. Environ. Chem. Lett. 11, 335-341

Monasterolo, M., Musicante, M. L., Valladares, G. R., Salvo, A. (2015) Soybean crops may benefit from forest pollinators. Agr. Ecosyst. Environ. 202, 217-222

Potts, S. G., Biesmeijer, J. C., Kremen, C., Neumann, P., Schweiger, O., Kunin, W. E. (2010) Global pollinator declines: trends, impacts and drivers. Trends Ecol. Evol. 25, 345-353

R Core Team (2016) R: A language and environment for statistical computing. R Foundation for Statistical Computing, Vienna, Austria. URL http://www.Rproject.org/

Raudenbush, A., Barker, J., Beers, L., Custer, S., Douridas, A., Estadt, M., Marrison, D., Richer, E., Beauzay, P., Tilmon, K. (2018) Pollinator in Soybean Update Ohio Summary. CFAES. Ohio State University Extension. https://cpb-us-w2.wpmucdn.com/u.osu.edu/dist/a/836 /files2018/09/Soybean-pollinators-2018-Ohio-Summary-273kyp9.pdf

Ricketts, T. H., Regetz, J., Steffan-Dewenter, I., Cunningham, S. A., Kremen, C., et al. (2008) Landscape effects on crop pollination services: are there general patterns? Ecol. Lett. 11, 499-515

Riedinger, V., Mitesser, O., Hovestadt, T., SteffanDewenter, I., Holzschuh, A., Rosenheim, J. A. (2015) Annual dynamics of wild bee densities: Attractiveness and productivity effects of oilseed rape. Ecology 96, 1351-1360

Roumet, P., Magnier, I. (1993) Estimation of hybrid seed production and efficient pollen flow using insect pollination of male sterile soybeans in caged plots. Euphytica 70, 61-67

Rust, R. W., Mason, C. E., Erickson, E. H. (1980) Wild bees on soybeans, Glycine max. Environ. Entomol. 9, 230-232.

Sardiñas, H. S., Ponisio, L. C., Kremen, C. (2016) Hedgerow presence does not enhance indicators of nest-site 
habitat quality or nesting rates of ground-nesting bees. Restor. Ecol. 24, 499-505

Smýkal, P., Trněný, O., Brus, J., Hanáček, P., Rathore, A., Roma, R. D., Pechanec, V., Duchoslav, M., Bhattacharyya, D., Bariotakis, M., Pirintsos, S., Berger, J., Toker, C. (2018) Genetic structure of wild pea (Pisum sativum subsp. elatius) populations in the northern part of the Fertile Crescent reflects moderate cross-pollination and strong effect of geographic but not environmental distance. PLoS ONE 13, e0194056

Steffan-Dewenter, I., Tscharntke, T. (1999) Effects of habitat isolation on pollinator communities and seed set. Oecologia 121, 432-440.

Suso, M. J., Bebeli, P. J., Christmann, S., Mateus, C., Negri, V., Pinheiro de Carvalho, M. A. A., Torricelli, R., Veloso, M. M. (2016) Enhancing Legume Ecosystem Services through an Understanding of Plant-Pollinator Interplay. Front. Plant Sci. 7, 333

Tscharntke, T., Klein, A. M., Kruess, A., SteffanDewenter, I., Thies, C. (2005) Landscape perspectives on agricultural intensification and biodiversity - ecosystem service management. Ecol. Lett. 8, 857-874
Westphal, C., Steffan-Dewenter, I., Tscharntke, T. (2003) Mass flowering crops enhance pollinator densities at a landscape scale. Ecol. Lett. 6, 961-965

Wheelock, M. J., Rey, K. P., O’Neal, M. E. (2016) Defining the Insect Pollinator Community Found in Iowa Corn and Soybean Fields: Implications for Pollinator Conservation. Environ. Entomol. 45, 1099-1106

Winfree, R., Williams, N. M., Dushoff, J., Kremen, C. (2007a) Native bees provide insurance against ongoing honey bee losses. Ecol. Lett. 10:1105-1113

Winfree, R., Williams, N. M., Gaines, H., Ascher, J. S., Kremen, C. (2007b) Wild bee pollinators provide the majority of crop visitation across land-use gradients in New Jersey and Pennsylvania, USA. J. Appl. Entomol. 45, 793-802

Zelaya, P. V., Chacoff, N. P., Aragón, R., Blendinger, P. G. (2018) Soybean biotic pollination and its relationship to linear forest fragments of subtropical dry Chaco. Basic Appl. Ecol. 32, 86-95.

Publisher's note Springer Nature remains neutral with regard to jurisdictional claims in published maps and institutional affiliations. 